\title{
Correction to: factors affecting residents transition from long term care facilities to the community: a scoping review
}

Shannon Freeman ${ }^{1 *}$, Kristen Bishop ${ }^{2}$, Lina Spirgiene ${ }^{3}$, Erica Koopmans ${ }^{4}$, Fernanda C. Botelho ${ }^{5}$, Trina Fyfe ${ }^{6}$, Beibei Xiong ${ }^{4,7}$, Stacey Patchett $^{8}$ and Martha MacLeod ${ }^{1}$

After the publication of the article [1] it came to our attention that the author name Fernanda C. Botelho was incorrectly included as Fernanda C. Bothelo. The correct spelling of the name is in the authors list of this correction and updated in the original article.

\begin{abstract}
Author details
${ }^{1}$ School of Nursing, University of Northern British Columbia, 3333 University Way, Prince George, BC V2N 4Z9, Canada. ${ }^{2}$ Faculty of Health Sciences, Health and Rehabilitation Sciences, Western University, 1151 Richmond St, London, ON N6A 3K7, Canada. ${ }^{3}$ Department of Nursing and Care, Lithuanian

University of Health Sciences, Mickevičiaus 9, -44307 Kaunas, LT, Lithuania.

${ }^{4}$ School of Health Sciences, University of Northern British Columbia, 3333 University Way, Prince George, BC V2N 4Z9, Canada. ${ }^{5}$ School of Public Health, University of Sao Paulo, Dr. Arnaldo Street 715, Sao Paulo, Brasília, SP 01246-904, Brazil. ' Northern Medical Program, University of Northern British Columbia, 3333 University Way, Prince George, BC V2N 4Z9, Canada. ${ }^{7}$ School of Nursing, Jilin University, 965 XinJiang Street, ChangChun, JiLin, ChangChun 130012, China. ${ }^{8}$ Department of Quality, Planning and Information, Northern Health, 543 Front Street, Quesnel, BC V2J 5K7, Canada.
\end{abstract}

Received: 12 October 2017 Accepted: 16 October 2017

Published online: 30 October 2017

\section{Reference}

1. Freeman $\mathrm{S}$, et al. Factors affecting residents transition from long term care facilities to the community: a scoping review. BMC Health Serv Res. 2017;17:689. DOl:10.1186/s12913-017-2571-y.

\footnotetext{
*Correspondence: shannon.freeman@unbc.ca

${ }^{1}$ School of Nursing, University of Northern British Columbia, 3333 University Way, Prince George, BC V2N 4Z9, Canada

Full list of author information is available at the end of the article
} 